Al-Mashrafiyah: Jurnal Ekonomi, Keuangan dan Perbankan Syariah

ISSN (p): 2597-4904 ISSN (e) : 2620-5661

Volume 4 , Nomor 2 , Oktober (2020), h. 42-56

https://doi.org/10.24252/al-mashrafiyah.v4i2.15194

\title{
INTERNALISASI NILAI-NILAI MACCA NA MALEMPU' DALAM ETIKA BISNIS ISLAM SEBAGI UPAYA MENINGKATKAN PELANGGAN CV. IDLAN WARANIE PERKASA (MABELLO INDONESIA)
}

\author{
Sa'adal Jannah \\ Pascasarjana UIN Alauddin Makassar \\ saadaljannah@stiba.ac.id \\ Siradjuddin, Syaharuddin \\ UIN Alauddin Makassar \\ siradjuddin.uin@gmail.com, Syaharuddinsyaharuddin7@,gmail.com
}

Received: 12-9-2020; Revised: 29-2-2020; Accepted; 20-10-2020

\begin{abstract}
Keywords:
ABSTRACT

Macca na malempu',

This study aims to describe the realization of the values of macca na malempu' and Islamic business Islamic Business ethics in an effort to increase customer satisfaction and the process of internalizing the values of macca Ethics, Internalization na malempu' in Islamic business etbics as an effort to increase customer satisfaction of Mabello Indonesia. This research uses field research methodology and library research with descriptive qualitative methods and analysis with a normative theology approach and literature study. The result of the research is that Mabello Indonesia in an effort to increase customer satisfaction has realized the values of macca na malempu', such as in product innovation and product quality control, Mabello Indonesia has also implemented Islamic business ethics in an effort to increase customer satisfaction by implementing 5 basic axioms, among others; unity, equilibrium, responsibility, free will, and benevolence, and the values of macca na malempu'are internalized in the 5 basic axioms of Islamic business ethics. The implications of research on business activities must uphold the value of regional local wisdom and for Muslim businessmen, the application of Islamic business ethics is absolutely necessary so that business activities are oriented to the world and the hereafter.
\end{abstract}

Kata Kunci: $\quad$ Penelitian ini bertujuan untuk mendeskripsikan realisasi nilai-nilai macca na malempu' dan Macca na malempu', etika bisnis Islam dalam usaha meningkatkan kepuasan pelanggan dan proses internalisasi Etika Bisnis Islam, nilai-nilai macca na malempu' dalam etika bisnis Islam sebagai upaya meningkatkan Internalisasia kepuasan pelanggan Mabello Indonesia. Penelitian ini menggunakan metodologi field research dan library research dengan metode kualitatif deskriptif dan analisis dengan pendekatan teologi normatif dan studi pustaka. Hasil penelitian adalab Mabello Indonesia dalam usaba meningkatkan kepuasan pelanggan telah merealisasikan nilai-nilai macca na malempu', seperti dalam inovasi produk dan pengawasan mutu produk, Mabello Indonesia juga telah menerapkan etika bisnis Islam dalam usaha meningkatkean kepuasan pelanggannya dengan penerapan 5 aksioma dasar antara lain; unity, equilibrium, responsibility, free will,dan benevolence, dan nilai-nilai macca na malempu' terinternalisasi dalam 5 aksioma dasar etika bisnis Islam. Implikasi penelitian kegiatan bisnis harus menjunjung tinggi nilai kearifan lokal daerah dan bagi pebisnis muslim, penerapan etika bisnis islami mutlak. dilakukan agar kegiatan bisnis berorientasi dunia dan akbirat 


\section{PENDAHULUAN}

Perdagangan dalam perspektif Islam adalah aspek kehidupan yang di-kelompokkan ke dalam masalah muamalah, berkenaan dengan hubungan yang ber-sifat horizontal dalam kehidupan manusia. Sekalipun sifatnya hubungan horizontal, namun harus sesuai dengan ajaran Islam yang mengacu pada Alquran dan hadis.

Tujuan suatu bisnis adalah untuk menciptkan para pelanggan merasa puas. Kualitas jasa yang unggul dan konsisten dapat menumbuhkan kepuasan pelanggan dan akan memberikan berbagai manfaat. Kepuasan pelanggan merupakan respon pelanggan terhadap ketidaksesuaian antara tingkat kepentingan sebelumnya dan kinerja aktual yang dirasakannya setelah pemakaian produk. (Fauzan \& Nuryana, 2014)

Suatu kegiatan bisnis harus dilakukan dengan etika atau norma-norma yang berlaku di masyarakat bisnis. Etika dan norma-norma itu digunakan agar para pengusaha tidak melanggar aturan yang telah ditetapkan dan usaha yang dijalankan mendapatkan berkah dari Allah swt, dan memperoleh simpati dari masyarakat. Pada akhirnya, etika dapat membentuk para pengusaha yang bersih dan dapat memajukan usaha yang dijalankan dalam waktu yang relatif lama. Dalam melaksanakan etika yang benar, akan terjadi keseimbangan hubungan antara pengusaha dengan masyarakat, konsumen, pemerintah, dan pihak-pihak lain yang berkepentingan. Kemudian menumbuhkan rasa saling membutuhkan diantara mereka yang pada akhirnya menumbuhkan rasa saling percaya sehingga usaha tersebut dapat ber-kembang sesuai yang diharapkan. (Sahri \& Huzaini, 2017)

Para pelaku bisnis sangat penting untuk menyadari bahwa praktik bisnisnya tidaklah berarti bebas nilai. Dengan peringatan semacam itu, bukan tidak mungkin para pelaku bisnis akan menanamkan bisnisnya secara halal dan sah melalui keputusan yang tepat yang diimbangi dengan perilaku yang dibenarkan syariat. (Barus \& Nuriani, 2016)

Banyak variabel yang mempengaruhi perilaku seseorang dalam melakukan kegiatan bisnis, salah satunya faktor yang mendorong perilaku manusia dalam kegiatan ekonomi adalah budaya. Budaya merupakan bagian pemikiran, akal budi atau adat istiadat. Secara tata bahasa, kebudayaan diturunkan dari kata budaya cenderung menunjuk pada pola pikir manusia. Pada era globaisasi saat ini, perilaku keseharian manusia merupakan refleksi dari pengetahuan, sikap dan perilaku yang merupakan kebiasaan yang dimiliki dan diwariskan anggota suatu masyarakat. (Iswanto, 2017)

Seperti kita ketahui, adanya krisis ekonomi dewasa ini, masyarakat yang hidup dengan menggantungkan alam dan mampu menjaga keseimbangan dengan lingkungannya dengan kearifan lokal yang dimiliki dan dilakukan tidak begitu merasakan adanya krisis ekonomi, atau pun tidak merasa terpukul seperti haknya masyarakat yang hidupnya sangat dipengaruhi oleh kehidupan modern. Maka dari itu kearifan lokal penting untuk dilestarikan dalam suatu masyarakat guna menjaga keseimbangan dengan lingkungan dan sekaligus dapat melestarikan lingkungannya. Berkembangnya kearifan lokal tersebut tidak terlepas dari pengaruh berbagai faktor yang akan mempengaruhi perilaku manusia terhadap lingkungannya. (Mujahidin, 2016)

Kegiatan ekonomi yang dilakukan masyarakat pada saat ini juga berkaitan erat dengan budaya yang dimiliki masing-masing individu. Indonesia mengenal kelompok masyarakat tertentu yang memiliki kemampuan dalam bidang ekonomi karena didorong oleh nilai-nilai budaya yang dimiliki, seperti suku Minang, suku Melayu, suku Aceh, suku Tionghoa, (Iswanto, 2017) termasuk suku Bugis-Makassar dimana peri-laku keseharian meupakan kebiasaan yang diwariskan oleh pendahulu sehingga minat terhadap kegiatan ekonomi khususnya berwirausaha lebih dominan.

Masyarakat Bugis, sejak dahulu dikenal memiliki sistem kehidupan dan tata nilai yang mereka pedomani dalam kehidupan tangga dan bermasyarakat. Nilai- nilai utama kebudayaan Bugis itu meliputi kejujuran (lempu'), kecendiakaan (macca), kepatutan (asitinajang), keteguhan (agettengeng), usaha (reso), prinsip malu (siri). (Rahim, 2011) Nilai-nilai tersebut diwariskan oleh leluhur bugis melalui pappang-aja (nasihat) dan paseng (amanat). (Yusuf, 2013)

Salah satu petuah Bugis-Makassar dalam urusan usaha dan pekerjaan, yaitu eppa'I naompo' adecengenna padangkangnge: Alempurengnge, assiwolompo-lengnge, amaccangangnge, na pongnge. Yang diartikan sebagai berikut; empat hal yang membawa kebaikan bagi pedagang; kejujuran, pergaulan, 
kecakapan/ ke-pintaran dan modal. (Mahmud, 2000) Petuah di atas, terdapat dua nilai utama yang harus dijunjung tinggi dalam aktivitas bisnis seseorang, yaitu macca (cakap/cerdas/pintar) dan malempu' (jujur).

Internalisasi nilai macca na malempu' dalam etika bisnis islam dapat diharapkan sebagai upaya dalam memuas-kan pelanggan sehingga mereka tetap bertahan. dan pendapatan suatu perusahaan bisa stabil atau bahkan meningkat.

\section{LANDASAN TEORI}

Kepuasan pelanggan didefinisikan sebagai tingkat perasaan seseorang setelah membandingkan kinerja (hasil) yang ia rasakan dibandingkan dengan harapannya. (Oliver, 2006) Perbandingan antara harapan dan kinerja tersebut akan menhasilkan perasaan senang atau kecewa di benak pelanggan. Apabila kinerja sesuai atau bahkan melebihi harapan, maka pelanggan akan merasa senang atau puas. Sebalik-nya apabila kinerja berada di bawah harapan, maka pelanggan akan merasa kecewa atau tidak puas. Kepuasan pelanggan juga didefinisikan sebagai tanggapan pelanggan, yaitu penilaian atas fitur-fitur suatu produk atau jasa, bahkan produk atau jasa itu sendiri, yang memberikan tingkat kesenangan dalam mengkonsumsi yang ber-hubungan dengan pemenuhan kebutuhan. (Sahri \& Huzaini, 2017) Diantara beragam cara untuk mengukr kepuasan pelanggan, maka dalam penelitian ini menggunakan konsep overall customer satisfaction atau mengukur kepuasan pelanggan secara keseluruhan yaitu dengan langsung menanyakan kepada pelanggan seberapa puas mereka dengan produk atau jasa spesifik tertentu dengan mengukur faktor kepuasan pelanggan terhadap produk, pelayanan dan harga.

Etika bisnis Islam merupakan suatu proses dan upaya untuk mengetahui hal-hal yang benar dan yang salah dan selanjutnya tentu melakukan hal yang benar ber-kenaan dengan produk, pelayanan perusahaan dengan pihak yang berkepentingan dengan tuntutan perusahaan. (Nawatmi, 2010) Landasan hukum etika bisnis Islam dapat kita temukan dalam beberapa ayat dalam Alquran. Antara lain dalam QS. Al-An'am/6: 152. Allah swt, berfirman:

"Dan janganlah kamu dekati harta anak yatim, kecuali dengan cara yang lebih bermanfa' at, hingga sampai ia dewasa. Dan sempurnakanlah takaran dan timbangan dengan adil. Kami tidak memikulkan beban kepada se-seorang melainkan sekedar kesanggupannya. Dan apabila kamu berkata, maka hendaklah kamu berlaku adil kendatipun dia adalah kerabat (mu), dan penubilah janji Allah. Yang demikian itu diperintabkan Allab kepadamu agar kamu ingat"

Adapun prinsip-prinsip etika bisnis menurut Alquran: Pertama, melarang bisnis yang dilakukan dengan proses kebatilan. Sebagaimana yang terangkum dalam surah Al-Nisa/4 : 29. Bisnis harus didasari kerelaan dan ke-terbukaan antara kedua belah pihak dan tanpa ada pihak yang dirugikan. (Syaifullah, 2014)

"Dan barangsiapa berbuat demikian dengan melanggar bak dan aniaya, maka Kami kelak akan memasukkannya ke dalam neraka. Yang demikian itu adalab mudah bagi Allab"

Etika dalam berbisnis seperti yang telah dontohkan Rasulullah saw, sewaktu muda dengan memperhatikan kejujuran, kepercayaan, dan ketulusan serta keramah-tamahan. Kemudian mengikutinya dengan penerapan prinsip bisnis dengan nilai siddiq, amānah, tabligh dan fatänah, serta nilai moral dan keadilan. (Syarif, 2016)

Sejumlah aksioma dasar sudah dirumuskan dan dikembangkan oleh para sarjana muslim. Aksioma-aksioma ini merupakan turunan dari hasil penerjemahan kontemporer akan konsepkonsep fundamental dari nilai moral Islami. Dengan begitu, aspek etika dalam bahasan ini sudah di insert dan diinternalisasikan dalam pengembangan sistem etika bisnis. 1. Unity (persatuan)Alam semesta, termasuk manusia adalah milik Allah swt, yang me-miliki kemahakuasaan sempurna atas makhluk-makhluk-Nya. Konsep tauhid berarti Allah sebagai Tuhan Yang Maha Esa menetapkan batas-batas tertentu atas perilaku manusia sebagai khalifah, untuk memberikan manfaat pada individu tanpa mengorbankan hak-hak individu lainnya; 2. Equilibrium (Keseimbangan) Beraktivitas di dunia kerja dan bisnis, Islam mengharuskan untuk ber-buat adil, tidak terkecuali kepada pihak 
yang tidak disukai. Pengertian adil dalam Islam diarahkan agar hak orang lain, hak lingkungan sosial, hak alam semesta dan hak Allah dan Rasul-Nya berlaku sebagai stakeholder dari peri-laku adil seseorang. Semua hak-hak tersebut harus ditempatkan sebagaimana mestinya (sesuai aturan syariah); 3. Free Will (Kehendak Bebas) Manusia sebagai khalifah di muka bumi sampai batas-batas tertentu mempunyai kehendak bebas untuk mengarahkan kehidupannya kepada tujuan yang akan dicapainya. Manusia dianugerahi kehendak bebas (free will) untuk membimbing kehidupannya sebagi khalifah. Berdasarkan aksioma kehendak bebas ini, dalam bisnis manusia mempunyai kebebasan untuk membuat suatu perjanjian atau tidak, melaksanakan bentuk aktivitas bisnis tertentu, berkreasi mengembangkan potensi yang ada; 4. Responsibility (Tanggung Jawab) Aksioma tanggung jawab individu begitu mendasar dalam ajaran-ajaran Islam. Terutama jika dikaitkan dengan kebebasan ekonomi. Penerimaan pada prinsip tanggung jawab individu ini berarti setiap orang akan diadili secara personal di hari kiamat kelak, tidak ada satu carapun bagi seseorang untuk melenyapkan perbuatan jahatnya kecuali dengan memohon ampunan Allah swt, dan melakukan perbuatan baik; dan 5. Benevolence (Ihsan) artinya melaksanakan perbuatan baik yang dapat memberikan kemanfaatan kepada orang lain, tanpa adanya kewajiban tertentu yang mengharuskan perbuatan tersebut atau dengan kata lain beribadah dan berbuat baik seakan-akan melihat Allah swt, jika tak mampu, maka yakinlah Allah melihat kita.

Kebudayaan dan pandangan hidup orang Bugis secara umum pada hakikat-nya sama dan serasi dengan kebudayaan dan pandangan hidup orang Makasar. Karena itu, membahas tentang budaya Bugis sulit dilepaskan dengan pembahasan tentang budaya Makassar. Menurut Abdullah bahwa dalam sistem keluarga atau dalam kekerabatan kehidupan manusia Bugis dan manusia Makassar, dapat dikata-kan hampir tidak terdapat perbeedaan. Lebih lanjut dikemukakan bahwa kedua kelompok suku bangsa ini (suku Bugis dan Makassar) pada hakikatnya merupakan suatu unit budaya. Sebab itu, apa yang berlaku dalam dunia manusia Bugis, berlaku pula manusia Makassar. (Mahmud, 2000)

Nilai macca na malempu' merupakan sebagian dari nilai utama masyarakat Bugis-Makassar. Nilai ini dijunjung tinggi dalam semua aspek kehidupan, termasuk dalam dunia dagang/ bisnis. Dalam petuah Bugis-Makassar bagi seorang pebisnis adalah "eppa'i naompo' adecengenna padangkangnge; alempurengnge', asiwolom-polangnge, amaccangnge, pongnge" artinya empat hal yang membawa kebaikan bagi pedagang; kejujuran, pergaulan, kecakapan/kecerdasan, dan modal. Dapat di-jelaskan bahwa; kejujuran menimbulkan kepercayaan. Kepercayaan adalah modal utama seorang pedagang dalam menjalankan usahanya. Pergaulan memperluas hubungan dagang. Dengan demikian, dapat menambah kemungkinan yang baik pula. Kecakapan memungkinkan perhitungan lebih matang dan memperkecil ke-rugian. Modal membantu melancarkan rencana. (Qamar, 2017) Dari petuah ini, ditemukan dua nilai utama yang harus dijunjung tinggi oleh pelaku bisnis, yaitu nilai macca dan malempu'.

Konsep nilai amaccangeng atau kecendekiaan sebagai nilai kearifan lokal Bugis-Makassar, di dalamnya terkandung sebagai suatu substansi tentang kejujuran, kebenaran, kepatutan, keikhlasan dan penyiasatan. To Ciung To Accana Luwu mengemukakan bahwa amaccangeng atau kecendekiaan adalah mencintai perbuatan benar dan kata-kata yang arif, jika menghadapi kesulitan, maka dipikirkannya matang-matang, dan selalu berhati-hati melaksanakan segala sesuatu. (Murtiningsih, 2019)

Dalam kosa kata bahasa Bugis-Makassar, jujur dimaknai dengan lempu' (Alempureng), yaitu sama dengan dengan lurus sebagai lawan kata bengkok. Menurut Matthes. B. F, bahwa dalam berbagai konteksnya, adakalanya kata lempu' diartikan juga dengan ikhlas, benar, baik atau adil. Sehingga adakalanya kata lempu' tersebut diperlawankan dengan kata culas, curang, dusta, khianat, seleweng, buruk, tipu, aniaya, dan lainnya. (Murtiningsih, 2019) 


\section{METODE PENELITIAN}

Penelitian ini merupakan penelitian lapangan (field research) dan penelitian pustaka (library research). Jenis penelitian yang digunakan adalah penelitian deskriptif kualitatif dengan pendekatan studi kasus dan teologis normatif. Data primer diperoleh langsung dari lapangan dengan mengamati dan mewawancarai pimpinan dan karyawan Mabello Indoesia. Untuk mengukur kepuasan pelanggan dengan menggunakan konsep overall customer satisfaction yaitu dengan menanyakan langsung kepuasan terhadap pelanggan dengan menyebarkan angket dalam bentuk google form yang disebarkan ke 40 pelanggan yang tersebar di beberapa wilayah di Indonesia. Indikator kepuasan pelanggan dihitung dengan menggunakan skala kesetujuan yang hasil persentase setiap indikatornya dirata-ratakan. Untuk menguatkan observasi, maka dilakukan wawancara langsung dengan 5 pelanggan. Semua pelanggan berjenis kelamin wanita, dengan latar belakang, umur, pendidikan, budget dan daerah yang berbeda-beda.

\section{HASIL DAN PEMBAHASAN}

\section{Deskripsi Hasil Penelitian}

1. Bentuk Nilai-Nilai Macca na Malempu' sebagai Upaya Meningkatkan Kepuasan Pelanggan Mabello Indonesia

Tabel 1. Implementasi Nilai-Nilai Macca na sebagai Upaya Meningkatkan Kepuasan Pelanggan Mabello Indonesia

\begin{tabular}{|c|c|c|}
\hline NO & Nilai- Nilai & Implemetasi \\
\hline 1 & Macca & $\begin{array}{l}\text { a. Inovasi tiada henti } \\
\text { b. Silturahim dan sharing session bagi para } \\
\text { mitra Mabello } \\
\text { c. Menggunakan alat berkualitas tinggi }\end{array}$ \\
\hline 2 & Malempu' & $\begin{array}{l}\text { a. Pengawasan mutu produk } \\
\text { b. Pendampingan pengawasan oleh ahli } \\
\text { farmasi } \\
\text { c. Hak mitra berupa pelatihan bisnis }\end{array}$ \\
\hline
\end{tabular}

Sumber: Data Prmer diolah, tahun 2020

Diantara usaha yang dilakukan oleh Mabello Indonesia dalam meningkat-kan kepuasan pelanggannya yaitu terus berinovasi dalam menciptakan produk-produk yang berkualitas, melakukan pengawasan terhadap jaminan mutu produk, serta melibatkan para konsumen dalam memberikan kritik dan sarannya sebagai bahan evaluasi Mabello Indonesia ke depannya. Dari pemaparan owner Mabello Indonesia menjadi bukti dari realisasi nilai macca na malempu'.

Macca yang dari bahasanya diartikan cakap, cerdas,atau intelek, maka nilai ini telah terimplikasi dari usaha berinovasi tanpa henti, memikirkan ide-ide baru dan mewujudkannya dalam produk yang berkualitas dan berdaya saing. Produk-produk yang dihasilkan diolah dengan mesin berkualitas serta bahan baku yang halal dan natural.

Macca juga dapat diartikan sebagai pannawa-nawa yang mengandung arti sebagai berikut; cinta kebenaran, selalu berhati-hati, dan bersifat tulus. Dengan demikian, macca dapat diartikan sebagai seseorang yang menyukai hal-hal yang baik dan berhati-hati dalam melakukan sesuatu dan tidak mementingkan diri sendiri. (Murtiningsih, 2019) Dalam hal ini, pimpinan Mabello juga memaparkan bahwa sistem pemasaran produk Mabello saat ini masih difokuskan pada penjulan online melalui kerjasama dengan para mitra yang tersebar di berbagai daerah di Indonesia. Mabello memahami bahwa tanpa mereka, maka pemasaran produk Mabello belum seluas dan sebesar saat 
ini. Maka dari itu, feedback dari Mabello untuk para mitra yaitu menyediakan wadah silaturahim via group WhatsApp.

Malempu'dalam arti bahasa yaitu lurus, lawan dari bengkok yang dimaknai dengan kejujuran. Makna lain malempu' dapat diartikan bagaimana seseorang dapat mempertahankan hak-hak mereka sesama manusia dan kewajiban terhadap penciptanya. Usaha Mabello dalam mengawasi mutu/kualitas produk dan dampingi dengan tenaga ahli farmasi untuk memastikan produk aman untuk ke-sehatan konsumen serta melibatkan para pelanggan dalam bentuk kritik dan saran pada produk yang telah dipasarkan telah mencerminkan nilai malempu' dalam usahanya meningkatkan kepuasan pelanggannya. Selain itu, mabello juga memastikan semua produknya telah lulus uji BPOM dan telah mengantongi keterangan halal dari MUI. Dalam beberapa kesempatan, demi mewujudkan pemasaran produk Mabello yang lebih maksimal, Mabello mengadakan berbagai event yang dikemas dalam bentuk motivasi dan pelatihan bagi para mitra, agar mereka mampu lebih bersinergi dalam mengembangkan bisnis ini.

\section{Bentuk Etika Bisnis Islam sebagai Upaya Meningkatkan Kepuasan Pelanggan Mabello Indonesia}

Tabel 2. Implementasi Etika Bisnis Islam sebagai Upaya Meningkatkan Kepuasan Pelanggan Mabello Indonesia

\begin{tabular}{|c|c|c|}
\hline No & Prinsip & Implementasi \\
\hline 1 & Unity & $\begin{array}{l}\text { a. Meraih keuntungan duniawi dan } \\
\text { ukhrawi } \\
\text { b. Menerima saran dan kritik dari } \\
\text { pelanggan } \\
\text { c. Pemenuhan hak mitra berupa } \\
\text { pelatihan bisnis }\end{array}$ \\
\hline 2 & Equilibrium & $\begin{array}{l}\text { a. Menerima saran dan kritik dari para } \\
\text { karyawan dan pelanggan } \\
\text { b. Memperlakukan sama semua karyawan } \\
\text { dan pelanggan }\end{array}$ \\
\hline 3 & Free Will & $\begin{array}{ll}\text { a. } & \text { Inovasi produk } \\
\text { b. Kebebasan karyawan untuk berkarya } \\
\text { dan bersinergi dalam mengembangkan } \\
\text { perusahaan }\end{array}$ \\
\hline 4 & Responsibility & $\begin{array}{l}\text { a. Menjaga mutu produk } \\
\text { b. Menjamin produk berasal dari bahan } \\
\text { baku yang halal dan berkualitas } \\
\text { c. Mengantongi surat BPOM dan Halal } \\
\text { MUI }\end{array}$ \\
\hline 5 & Benevolence & $\begin{array}{l}\text { a. Kajian Islami } \\
\text { b. Buka puasa bersama } \\
\text { c. Sedekah Jumat } \\
\text { d. Pemabgian handsinitizer } \\
\text { e. Tanggap bencana Donggala, Palu, Riau } \\
\text { dll. }\end{array}$ \\
\hline
\end{tabular}

Sumber: Data primer, diolah. Tahun 2020 
Berikut penerapan prinsip dasar etika bisnis dalam usaha meningkatkan kepuasan pelanggan Mabello Indonesia. Dari hasil wawancara dengan owner, dapat disimpulkan bahwa dalam aktivitas bisnis, keuntungan duniawi bukanlah menjadi satu-satunya tujuan. Namun tujuan terbesar baginya adalah bagaimana bisa meraih surga dan terhindar dari neraka dengan berdagang. Dan hal ini yang turut menjadi usaha Mabello dalam meningkatkan kepuasan pelanggan, yaitu memberikan wadah dalam pemenuhan hak bagi unsur-unsur yang berperan langsung dalam peng-embangan perusahaan. Salah satunya adalah para mitra/pelanggan tetap mereka. Mereka diberikan ruang untuk menyampaikan keluhan, maupun apresiasi terhadap Mabello. Tidak hanya itu, sebagai bentuk perhatian Mabello terhadap pelangganya, Mabello dalam beberapa kesempatan mengadakan event dalam bentuk pelatihan bisnis yang tentunya sangat dibutuhkan oleh para mitra untuk mengembangkan bisnisnya. Dalam hal ini, Mabello telah mengimplementasikan tugasnya sebagai khalifah yang memberikan manfaat kepada individu tanpa mengorbankan hak individu lainnya. Ii adalah implementasi dari prinsip unity (kesatuan/tauhid).

Pemaparan karyawan Mabello bahwa pimpinan Mabello berlaku adil/seimbang kepada setiap karyawan maupun pelanggan-nya. Setiap dari mereka didengarkan keluhan dan sarannya. Sehingga saran-saran perbaikan datang dari siapa saja yang tentunya menginginkan produk Mabello jauh lebih berkembang dan berkualitas. Dan ini menjadi salah satu cara menjaga dan meningkatkan kepercayaan dan kepuasan pelanggan Mabello. Hal ini merupakan implementasi dari prinsip equilibrium (keseimbangan).

Keberadaan para karyawan dan mitra menjadikan Mabello selalu bijaksana dalam memberikan kebebasan kepada mereka untuk berkarya, bersinergi, maupun memberikan saran dan kritikan demi majunya perusahaan. Mabello menyadari, dengan adanya free will yang ditempakan kepada orang-orang yang turut andil bersama di bawahnya, mampu menciptakan produk-produk yang inovatif dan up to date. Sebagai buktinya Mabello yang awalnya hanya memiliki satu jenis produk berupa bedda' lotong/lulur hitam, saat ini Mabello telah memiliki 10 jenis produk dengan 22 varian yang berkualitas. Ini merupakan implementasi dari prinsip free will (kehendak bebas).

Dalam usaha meningkatkan kepuasan pelanggannya, maka Mabello menjunjung tinggi nilai tanggung jawab ini pada setiap produk yang dipasarkn. Di awal merintis usaha ini, Mabello yakin tidak perlu menambah pengawet pada setiap produknya demi keselamatan para konsumennya. Karena di awal mem-produksi, pihak Mabello meyakini ada efek negatif pada setiap pengawet yang dicampurkan dalam setiap produk. Karena itu, lulur hitam Mabello di awal kemunculannya, harus disimpan di dalam lemari es agar kualitasnya terjaga. Namun setelah proses belajar dan sharing dengan banyak pihak, barulah mereka memahami bahwa campuran pengawet dalam jumlah yang wajar, tidaklah membahayakan konsumen. Demi ketahanan produk yang lebih lama dan seiring bertambahnya jumlah produksi, maka Mabello akhirnya men-campur setiap produknya dengan pengawet dalam kadar yang diizinkan dan telah mengantongi BPOM. Hal ini, termasuk diantara bentuk tanggungjawab Mabello terhadap produk yang akan dikonsumsi oleh pelanggannya. Selain itu, diantara bentuk tanggungjawab Mabello adalah pengawasan mutu setiap produk yang rutin dilakukan. Demi menjamin agar produk yang dihasilkan berasal dari bahan yang halal dan berkualitas. Hal inilah yang cukup menarik minat konsumen dan meningkatnya kepuasan pelanggan karena setiap produk Mabello dijamin kehalalan dan kualitas bahan bakunya. Hal ini sejalan dengan pendapat salah seorang pelanggan Mabello, Suciani yang mengakui kepuasannya sebagai pelanggan Mabello. Ia menuturkan, bahwa diantara hal yang membuatnya puas sebagai pelanggan, karena produk Mabello telah mengantongi BPOM dan keterangan Halal dari MUI. Selain itu, wangi khas rempah-rempah dari setiap produk, memberi kesan tersendiri bagi Suci.Usaha ini merupakn implementasi dari prinsip responsibility (tanggung jawab).

Mabello dalam kesibukan-nya mengurus bisnis, ternyata ini bukan menjadi alasan untuk tidak berbuat ihsan kepada orang-orang yang membutuhkan di sekitarnya. Seperti disebut-kan oleh Aliyah, Mabello sejak berdirinya selalu melakukan kegiatan ke-Islaman dalam lingkup perusahaan seperti kajian Islami maupun acara buka puasa bersama, kegiatan sosial 
seperti sedekah Jumat dan pembagian hand-sanitizer di masa pandemi saat ini, serta kegiatan tanggap bencana di Donggala, Pal, Riau dll. Hal ini dapat meyakinkan pelanggan bahwa hasil penjualan produk Mabello tidak hanya untuk keuntungan semata, tetapi sebagian dari hasil penjualan disisihkan untuk kegiatan amal. Ini merupakan implementasi dari prinsip benevolence (Kebajikan).

\section{Internalisasi Nilai-Nilai Macca na Malempu' dalam Etika Bisnis Islam sebagai Upaya Meningkatkan Kepuasan Mabello Indonesia.}

Suku Bugis-Makassar termasuk diantara kelompok masyarakat yang senan-tiasa menjunjung tinggi nilai kearifan lokal dalam segala aspek kehidupan mereka, termasuk dalam dunia bisnis. Diantara nilai-nilai lokal yang harus ada dalam bisnis adalah nilai macca na malempu'. Dalam buku kumpulan petuah Bugis-Makassar, kedua nilai ini diretas dalam beberapa nilai;

a. Macca/Amaccang

1) Malempu'i namatette: teguh dalam kejujuran

2) Makurang cai' $i$ : Kurang marah

3) Maradde'na rigau' sitinajae: Selalu berbuat baik

4) Makurang pauni ripadanna rupa tau: Kurang bicara pada sesama manusia (pada hal-hal yang tidak bermanfaat)

5) Naitai riolona gau'e najeppuini munrinna: Menyelami latar belakang persoalan dan mengetahui benar akibatnya

6) Mappasitinajai ada mappasiratang wenru: Melayakkan kata dan me-mantaskan sesuatu

7) Saroi mase risilasanae pakekutanai alena: Merendahkan diri selayaknya selaras dengan harga dirinya

8) Pau ada matojo enrengnge ada malemma: (Dapat) mengucapkan kata tegas dan lemah lembut

9) Naiya accae ripatoppoi jekkeo' aggatti' alliri, narekko teai mareddu' mapoloi: Kepandaian yang disertai kecurangan ibarat tiang rumah (Bugis-Makassar), kalau tidak tercabut ia patah

10) Naiya riasengnge acca de' gaga masusa napogau': Yang dinamakan cakap tidak ada yang sulit dilaksanakan,

11) ......De' to ada masusa nabali ada madeceng malemmae' : ...... tidak ada juga pembicaraan yang sulit disambung dengan kata-kata yang baik serta lemah lembut,

12) ......mateppe’i ripadanna tau :......Percaya kepada sesama manusia,

b. Lempu'/ Alempureng

1) Naiya riasengnge lempu' makessingngi gau'na: Yang dinamakan jujur, perbuatannya baik

2) .......Madeceng ampena: ......tingkah lakunya baik

3) ......Patujui nawa-nawanna: ....pikirannya benar

4) ......Nametau' ri Dewa ta': .....Takut kepada Tuhan

5) Narekko salai naengaumi assalanna: Kalau bersalah ia mengakui ke-salahannya

6) Narekko rionroi sala nadadampengengngi tau ripasalanna: Kalau di-tempati bersalah ia memaafkan orang yang bersalah

7) Narekko risanrekini de'napakecoangngi: Kalau disandari ia tidak menge-cewakan

8) Narekko rirennuangngi de'na pabbelle: Kalau dipercaya ia tidak menipu

9) Narekeo majjanciwi narupaiwi jancinna: Kalau berjanji ia menepati janji

10) Naiya appongenna lempu'e duampuangemmi, iyapa tapoadai kadopi' molai, iyapa tapogau'i kadopi liwnriwi taune: Pangkal kejujuran ada dua; baru dikatakan kalau bersedia pula melaksanakan, baru diperbuat kalau sanggup melakukan lebih dahulu, kemudian orang lain.

11) Riasalaie naddampeng: Disalahi ia memaafkan

12) Riparennuangngi temmacekko, bettuanna risanresie teppabelleang : Dipercaya ia tidak mengecewakan, artinya disandari ia tidak menipu

13) Temmangowaengngi taniya olona: Tidak serakah pada yang bukan haknya

14) Tennaseng deceng rekeko' deceng rialena; iyami naseng deceng rekeko nassamarini pudecengngi : Tidak menganggap sebagai kebaikan jika kebaikan itu hanya untuk dirinya, yang dinamakan kebaikan kalau kebaikan itu dapat dinikmati bersama. 
15) Naiya tau malempu'e manguru' mana'i tau sugi'e: Orang yang jujur adalah ahli waris orang kaya.

Retasan nilai macca na malempu' di atas dapat diinternalisasikan dalam aksioma dasar etika bisnis Islam sebagai berikut;

Tabel 3. Internalisasi Nilai-Nilai Macca na Malmepu'dalam Etika Bisnis Islam sebagai Upaya Meningkatkan Kepuasan Pelanggan Mabello Indonesia

\begin{tabular}{|c|c|c|c|}
\hline No & Nilai-nilai Macca & Nilai- nilai Malempu' & $\begin{array}{c}\text { Aksioma Dasar } \\
\text { Etika Bisnis Islam }\end{array}$ \\
\hline 1 & Maradde'na rigau' sitinajae & Metau' ri Dewa ta' & Unity \\
\hline 2 & $\begin{array}{l}\text { - Mappasitinajai ada } \\
\text { mappasiratang wenru } \\
\text { - Pau ada matojo enrengnge } \\
\text { ada malemma } \\
\text { - Makurang pauwi } \\
\text { ripadanna rupa tau }\end{array}$ & $\begin{array}{l}\text { - Temmangowaengngi taniya olona } \\
\text { - Tennaseng deceng rek.ko' deceng } \\
\text { rialena; iyami naseng deceng rek.ko } \\
\text { nassamarini pudecengngi } \\
\text { - Naiya appongenna lempu'e } \\
\text { duampuangemmi, iyapa tapoadai } \\
\text { kadopi' molai, iyapa tapogau'i } \\
\text { kadopi liwuriwi tawne }\end{array}$ & Equilibrium \\
\hline 3 & $\begin{array}{l}\text { - Naiya riasengnge acca de' } \\
\text { gaga masusa napogau' } \\
\text { - De' to ada masusa nabali } \\
\text { ada madeceng malemmae' }\end{array}$ & & Free Will \\
\hline 4 & $\begin{array}{l}\text { - Malempu'i namatette } \\
\text { - Naitai riolona gau'e } \\
\text { najeppuiwi munrinna }\end{array}$ & $\begin{array}{l}\text { - Narekko salai naengaumi } \\
\text { assalanna } \\
\text { - Narek.ko risanrekini } \\
\text { de'napakecoangngi } \\
\text { - Narek.ko rirennuangngi de'na } \\
\text { pabbelle } \\
\text { - Riparennuangngi temmacek.ko }\end{array}$ & Responsibility \\
\hline 5 & $\begin{array}{l}\text { - Makurang cai’i } \\
\text { - mateppe'i ripadanna tau }\end{array}$ & $\begin{array}{l}\text { - Naiya riasengnge lempu' } \\
\text { makessingngi gau'na } \\
\text { - Madeceng ampena } \\
\text { - Patujui nawa-nawanna } \\
\text { - Narekko rionroi sala } \\
\text { nadadampengengngi tau ripasalanna } \\
\text { - Riasalaie naddampeng } \\
\text { - Naiya tau malempu'e manguru' } \\
\text { mana'i tau sugi'e }\end{array}$ & Benevolence \\
\hline
\end{tabular}

Sumber: Data Primer, diolah. Tahun 2020

Dalam tabel diatas, dapat disimpulkan bahwa nilai-nilai macca na malempu terinternalisasi dengan aksioma dasar etika bisnis Islam. Nilai- nilai macca di-antaranya adalah Maradde'na rigau' sitinajae (selalu berbuat baik) dan nilai-nilai malempu' diantaranya Nametau' ri Dewa ta' (takut kepada Tuhan) terinternalisasi ke dalam unity (kesatuan/tauhid).

Nilai-nilai macca lainnya yaitu Mappasitinajai ada mappasiratang wenru (melayakkan kata dan memantaskan sesuatu), Pau ada matojo enrengnge ada malemma ((Dapat) mengucapkan kata tegas dan lemah lembut), dan Makurang pawwi ripadanna rupa tau, Kurang bicara pada sesama manusia (pada hal-hal yang tidak bermanfaat) serta nilai-nilai malempu' lainnya yaitu, Temmangowaengngi taniya olona (tidak serakah pada yang bukan haknya), Tennaseng deceng rek.ko' deceng rialena; iyami naseng deceng rekko nassamarini pudecengngi (tidak menganggap sebagai kebaikan jika kebaikan itu hanya untuk dirinya, yang dinamakan kebaikan kalau kebaikan itu dapat dinikmati bersama), dan Naiya appongenna lempu'e duampuangemmi, iyapa tapoadai kadopi' molai, iyapa tapogau'i kadopi liwnriwi taune (pangkal kejujuran ada 
dua; baru dikatakan kalau bersedia pula melaksanakan, baru diperbuat kalau sanggup melakukan lebih dahulu, kemudian orang lain) terinternalisasi dengan equilibrium (keseimbangan/keadilan).

Nilai-nilai macca selanjutnya yaitu, Naiya riasengnge acca de' gaga masusa napogau' (yang dinamakan cakap tidak ada yang sulit dilaksanakan), dan De' to ada masusa nabali ada madeceng malemmae' (tidak ada juga pembicaraan yang sulit disambung dengan kata-kata yang baik serta lemah lembut) terinternali-sasi dengan free will (kebebasan). Sementara belum ada nilai-nilai malempu' yang terinternalisasi dengan aksioma ini.

Nilai-nilai macca yang lain yaitu, Malempu'i namatette (teguh dalam kejujuran), dan Naitai riolona gau'e najeppuiwi munrinna (menyelami latar belakang persoalan dan mengetahui benar akibatnya) serta nilai-nilai malempu' yaitu, Narekko salai naenganwi assalanna (kalau bersalah ia mengakui kesalahan-nya), Narekko rirennuangngi de'na pabbelle (kalau dipercaya ia tidak menipu), dan Riparennuangngi temmacekko, bettuanna risanresie teppabelleang (dipercaya ia tidak mengecewakan, artinya disandari ia tidak menipu) terinternalisasi dalam responsibility (tanggungjawab).

Nilai-nilai macca yaitu, makurang cai'i ( kurang marah), dan mateppe'i ripadanna tau (percaya kepada sesama manusia) serta nilai-nilai malempu' yaitu; Naiya riasengnge lempu' makessingngi gau'na (yang dinamakan jujur, perbuatannya baik), Madeceng ampena (tingkah lakunya baik), Patujui nawanawanna (pikirannya benar), Narekko rionroi sala nadadampengengngi tau ripasalanna (kalau ditempati bersalah ia memaafkan orang yang bersalah), Riasalaie naddampeng (disalahi ia memaafkan), Naiya tau malempu'e manguru' mana'i tau sugi'e (orang yang jujur adalah ahli waris orang kaya) terinternalisasi dalam benevolence (kebajikan/ihsan). Sementara usaha Mabello sebagai upaya peningkatan kepuasan pelanggannya yang telah terjabarkan dalam implementasi nilai-nilai macca na malempu' secara tidak langsung telah terinternalisasi ke dalam etika bisnis Islam dengan melihat implementasinya dalam lima aksioma dasar etika bisnis Islam.

\section{Karakteristik Pelanggan Mabello}

Tabel 4. Rata-Rata Umur Pelanggan Mabello

\begin{tabular}{|c|c|c|}
\hline Umur & Frekuensi & Persentase \\
\hline $17-30$ tahun & 34 orang & $85 \%$ \\
\hline $31-40$ tahun & 6 orang & $15 \%$ \\
\hline
\end{tabular}

Sumber: Data Primer, diolah. Tahun 2020

Survei umur bertujuan untuk mengetahui segmen pasar Mabello di-kisaran umur pelanggan. Selain itu, Mabello merupakan produk kosmetik atau kecantikan yang pada umumnya konsumennya adalah wanita, sebagaimana terlihat pada Tabel 4.

Tabel 4. diketahui bahwa sebanyak 85\% pelanggan Mabello berumur pada kisaran 1730 tahun. Dapat dipahami bahwa produk Mabello banyak diminati mulai gadis remaja hingga yang berumur 30 tahun yaitu mereka yang masih berada pada usia produktif. Adapun sisanya yaitu 15\% berumur 31-40 tahun. Ini menggambar-kan bahwa produk Mabello cocok bagi semua usia, baik untuk dikonsumsi sendiri, maupun untuk dijual kembali, khususnya bagi mereka yang tengah menikmati waktunya menjadi mitra Mabello.

Tabel 5. Rata-Rata Pendidikan Terakhir Mabello

\begin{tabular}{|c|c|c|}
\hline Pendidikan Terakhir & Frekuensi & Persentase \\
\hline SLTP & 1 Orang & $2,5 \%$ \\
\hline SMA/MAN & 3 orang & $7,5 \%$ \\
\hline D3 & 2 orang & $5 \%$ \\
\hline S1 & 34 orang & $85 \%$ \\
\hline
\end{tabular}




\begin{tabular}{|c|c|c|}
\hline S2 & - & - \\
\hline S3 & - & - \\
\hline
\end{tabular}

Sumber: Data Primer, diolah. Tahun 2020

Survei terkait dengan pendidikan terakhir pelanggan Mabello bertujuan untuk mengetahui bagaimana besar pengetahuan mereka terhadap produk Mabello dilihat dari latar belakang pendidikannya.

Tabel 5 diketahui bahwa persantase pendidikan terakhir pelanggan Mabello sebanyak 2,5\% mereka berasal dari SLTP, 7,5\% berasal dari SMA/MAN, 5\% berasal dari alumni Diploma 3, dan $85 \%$ berasal dari pendidikan strata satu. Dari persantase ini dapat disimpulkan bahwa sebagian besar pelanggan Mabello ada lulusan universitas negeri maupun swasta. Ini membuktikan bahwa produk Mabello adalah pilihan orang-orang cerdas dan berpendidikan. Selain puas dengan mengkonsumsi produknya, mereka juga manfaatkan dalam peluang bisnis sebagai mitra Mabello.

Tabel 6. Rata-Rata Pekerjaan Pelanggan Mabello

\begin{tabular}{|c|c|c|}
\hline Pekerjaan & Frekuensi & Persentase \\
\hline IRT & 34 orang & $85 \%$ \\
\hline PNS & 3 orang & $7,5 \%$ \\
\hline Karyawan & 1 orang & $2,5 \%$ \\
\hline Mahasiswi/Pelajar & 2 orang & $5 \%$ \\
\hline
\end{tabular}

Sumber: Data Primer, diolah. Tahun 2020

Tabel 6. terlihat bahwa persentase pekerjaan para pelanggan Mabello dihasilkan bahwa sebanyak 85\% merupakan Ibu rumah tangga, 7,5\% adalah Pegawai negeri Sipil, 2,5\% adalah karyawan swast, dan sisanya $5 \%$ adalah mahasiswi maupun pelajar. Dapat disimpulkan bahwa rata-rata dari pelanggan Mabello adalah para ibu rumah tangga yang sebagian besar aktivitasnya dilakukan rumah. Bahkan ini juga dimanfaatkan sebagai wadah bisnis mereka khusunya yang telah menjadi mitra. Tidak hanya itu, para mitra Mabello juga berasal dari para Pegawai Negeri Sipil dan karyawan swasta yang notabene kebanyakan aktivitasnya di tempat kerja, tapi itu menjadi alasan untuk tidak memanfaatkan momen bisnis dengan Mabello. Sisanya adalah para mahasiswi dan pelajar yang sudah berani mencoba masuk dalam dunia bisnis di tengah kesibukan belajar mereka. Sebagai mitra, tentunya mereka telah membuktikan bahwa produk Mabello layak dijadikan ajang bisnis setelah melihat khasiat dari tiap-tiap produk.

Tabel 7. Wilayah Domisili Pelanggan Mabello

\begin{tabular}{|c|c|c|}
\hline Daerah & Frekuensi & Persantase \\
\hline Makassar & 12 orang & $30 \%$ \\
\hline Luar Makassar & 28 orang & $70 \%$ \\
\hline
\end{tabular}

Sumber: Data Primer. Diolah. Tahun 2020

Tabel 7. menggambarkan persentase wilayah domisili pelanggan Mabello didapatkan bahwa 30\% pelanggan Mabello berasal dari Makassar, sisanya sekitar 70\% tersebar di daerah luar Makasar seperti Bone,Bantaeng, Maros, Gowa, Luwu Timur, Bandar Lampung, Bau-Bau, Sulawesi Tenggara, Tidore Maluku Utara, Jakarta, Muna, Bekasi dan daerah-daerah lain yang belum disurvei. Makassar sebagai daerah pusat Mabello tetap menjadi daerah no 1 persebaran 
pelanggan maupun mitra Mabello, sementara pelanggan lainnya tersebar dalam banyak wilayah di berbagai provinsi. Sulawesi Selatan termasuk provinsi tingkat pertama dalam penyebaran pelanggan, sisanya tersebar di beberapa provinsi lain.

Tabel 8. Frekuensi Belanja Setiap Bulan

\begin{tabular}{|c|c|c|}
\hline Frekuensi Belanja & Frekuensi & Persentase \\
\hline Sekali & 14 orang & $35 \%$ \\
\hline 2 kali & 14 orang & $35 \%$ \\
\hline 3 kali & 1 orang & $2,5 \%$ \\
\hline Lebih dari 3 kali & 11 orang & $28 \%$ \\
\hline
\end{tabular}

Sumber: Data Primer, diolah. Tahun 2020

Tabel 8. terlihat bahwa persentase frekuensi belanja setiap bulannya. Dihasilkan bahwa pelanggan yang belanja sekali dalam sebulan sekitar 35\%, pelanggan yang belanja dua kali dalam sebulan sekitar 35\%, pelanggan yang belanja tiga kali dalam sebulan 2,5\% dan pelanggan yang belanja lebih dari tiga kali sebanyak $28 \%$. Frekuensi belanja tetntunya ditentukan dari seberapa tinggi kepuasan pelanggan terhadap produk, baik untuk dikonsumsi sendiri maupun untuk dijual kembali. Sebanyak 35\% adalah pelanggan yang belanja sekali dan dua kali dalam sebulan, jumlah ini bisa diasumsikan mereka adalah pelanggan atau mitra yang baru. Tapi $28 \%$ banyak dari mereka yang belanja lebih dari tiga kali dalam sebulan, bisa diasumsikan mereka adalah para mitra yang sudah mulai atau telah berkembang di daerah masing-masing.

Tabel 9. Pengeluaran Sekali Transaksi

\begin{tabular}{|l|c|}
\hline \multicolumn{1}{|c|}{ Pengeluaran Sekali Trsansaksi } & Persantase \\
\hline Rp 50.000- Rp 100.000 & $24,4 \%$ \\
\hline Rp 150.000- Rp 300.000 & $14,6 \%$ \\
\hline Rp 350.000-Rp 1.000.000 & $22 \%$ \\
\hline$>$ Rp 1.000.000 & $39 \%$ \\
\hline
\end{tabular}

Sumber: Data Primer, diolah. Tahun 2020

Tabel 9. terlihat bahwa persentase jumlah nominal sekali transaksi. Dihasilkan bahwa sebanyak 24,4\% adalah pelanggan yang transaksinya sekitar Rp 50.000 - Rp 100.000 sekali belanja. Sebanyak 14,6\% adalah pelanggan yang transaksinya sekitar Rp 150.000 - Rp 300.000 sekali belanja. Sebanyak 22\% adalah pelanggan yang transaksinya Rp 300.000 - Rp 1.000 .000 sekali belanja. Dan sisanya 39\% adalah pelanggan yang transaksinya lebih banyak dari Rp 1.000.000. Dari persentase ini dapat diasumsikan bahwa sebagian besar pelanggan Mabello mampu membeli banyak produk sekali transaksi untuk dijual kembali, dan sebagiannya untuk dikonsumsi sendiri. Dapat diperhatikan bahwa kepuasan Mabello terlihat sangat tinggi, terkhusus bagi mereka para mitra yang telah mampu meyakinkan pasar tentang kualitas produk Mabello.

\section{Kepuasan Pelanggan Mabello Indonesia}

Cara mengukur kepuasan pelanggan pada penelitian ini adalah menyebar-kan kuisioner berupa google form kepada pelanggan Mabello yang tersebar di berbagai daerah di seluruh Indonesia. Di dapatkan sekitar 40 responden yang semuanya adalah wanita dengan latar belakang dan umur 
yang berbeda-beda. Perlu diketahui bahwa rata-rata dari responden adalah yang awalnya sebagai pelanggan hingga akhirnya menjadi mitra Mabello, artinya mereka membeli lalu kemudian dijual kembali. Kepuasan pelanggan adalah persepsi pelanggan Mabello Indonesia atas keragaman kualitas produk, kualitas pelayanan, dan harga dalam hubungan memenuhi harapannya. Kepuasan pelanggan (Overall Customer Satisfction) menurut Fornel yaitu dengan tiga indikator: (Tjiptono, 2006) a. Kepuasan pelanggan pada kualitas produk

Tabel 10. Kepuasan Pelanggan Mabello pada Kualitas Produk Mabello

\begin{tabular}{|c|c|}
\hline Sangat Setuju & $54 \%$ \\
\hline Setuju & $32 \%$ \\
\hline Cukup Setuju & $14 \%$ \\
\hline Tidak Setuju & $0 \%$ \\
\hline Sangat Tidak Setuju & $0 \%$ \\
\hline
\end{tabular}

Sumber: Data Primer, diolah. Tahun 2020

Tabel 10. terlihat bahwa persentase kepuasan pelanggan pada kualitas produk Mabello. Berman dan Evans menjelaskan bahwa kualitas produk diukur dari; a) Width and depth of assosrtment (produk yang dipasarkan terdiri dari berbagai jenis item dan varian); b) Merchandise quality (produk yang dipasarkan memiliki khasiat tinggi sehingga menarik banyak pembeli); c) Level of innovativeness (produk sangat menarik dan up to date), dan d) Inventory control (produk terbuat dari bahan halal dan berkualitas). (Berman \& Evans, 2003)

Hasil survei menggunakan skala kesetujuan dengan hasil persentase yang telah dirata-ratakan sebagai berikut; sangat setuju sebanyak $54, \%$, setuju sebanyak 32,\%, cukup setuju sebanyak $14 \%$, tidak setuju sebanyak $0 \%$ dan sangat tidak setuju sebanyak $0 \%$. Dari hasil survei ini dapat disimpulkan bahwa pelanggan Mabello sangat puas dengan kualitas produk Mabello yang dipasarakan. Baik dalam hal jenis produk, khasiat produk, casing produk, dan bahan baku produk.

b. Kepuasan Pelanggan pada Kualitas Pelayanan

Tabel 11. Kepuasan Pelanggan pada Kualitas Pelayanan Produk Mabello

\begin{tabular}{|c|c|}
\hline Sangat Setuju & $46 \%$ \\
\hline Setuju & $44 \%$ \\
\hline Cukup Setuju & $10 \%$ \\
\hline Tidak Setuju & $0 \%$ \\
\hline Sangat Tidak Setuju & $0 \%$ \\
\hline
\end{tabular}

Sumber: Data Primer, diolah. Tahun 2020

Tabel 11. terlihat bahwa persentase kepuasan pelanggan pada kualitas pelayanan Mabello. Zeithaml \& Bitner menjelaskan ada lima dimensi kualitas pelayanan, yaitu reliability (keandalan), responsiveness (daya tanggap), assurance (jaminan), empathy (kepedulian) dan tangibles (bukti fisik) (Zethaml \& Bitner, 2001) yang dapat diurai dengan beberapa indikator sebagai berikut: a) Memberikan pelayanan penjualan sesuai dengan jam operasional kantor; b) Mampu memenuhi permintaan pelanggan dengan tepat; c) Karyawan memberikan pelayanan kepada pelanggan dengan sigap dan tanggap; d) Karyawan mampu merespon permintaan dengan baik; e) Karyawan mempunyai pengetahuan memadai untuk menjawab pertanyaan pelanggan berkaitan dengan produk; f) Karyawan secara konsisten bersikap ramah dan sopan kepada pelanggan; g) Karyawan selalu mengutamakan kepentingan pelanggan; dan h) Karyawan bersedia merespon keluhan pelanggan.

Hasil survei menggunakan skala kesetujuan dengan persentase yang telah dirataratakan, maka diperoleh hasil sebagai berikut; Sangat Setuju 46\%, Setuju 44\%, Cukup Setuju 
10\%, Tidak Setuju 0\%, dan Sangat Tidak Setuju 0\%. Dari persentase tersebut dapat disimpulkan bahwa pelanggan Mabello sangat puas pada pelayanan. Baik dalam waktu pelayanan, pemenuhan per-mintaan pelanggan dengan tepat, pelayanan dengan sigap dan tanggap, pengetahuan karyawan terhadap produk, pelayanan yang ramah, mengutama-kan kepentingan dan karyawan yang selalu siap merespon keluhan pelanggan.

\section{PENUTUP}

Mabello Indonesia, dalam usaha meningkatkan kepuasan pelanggan-nya telah merealisasikan nilai-nilai macca na malempu'. Maka nilai ini telah terimplikasi dari usaha berinovasi tanpa henti, memikirkan ide-ide baru dan mewujudkannya dalam produk yang berkualitas dan berdaya saing. Produk-produk dihasilkan diolah dengan mesin berkualitas serta bahan baku yang halal dan natural. Selain itu, Mabello memberikan feedback kepada para mitra yang selalu bersinergi memasarkan produk dengan membuat grup Whats $A p p$ sebagai wadah silaturahim, dan sharing tentang strategi pemasaran yang baik. Adapun implementasi nilai-nilai malempu' dalam usaha meningkatkan kepuasan pelanggan, Mabello melakukan pengawasan mutu produk dengan didampingi oleh tenaga ahli farmasi untuk memastikan produk aman dikonsumsi oleh pelanggan, serta me-libatkan para pelanggan dalam bentuk kritik dan saran pada produk yang telah dipasarkan. Produk Mabello juga telah mengantongi izin dari BPOM dan keterangan halal dari MUI. Selain itu, memberikan hak-hak mitra Mabello dengan mengadakan berbagai kegiatan silaturahim maupun pelatihan.

Penerapan etika bisnis Islam dalam usaha meningkatkan kepuasan pelanggan Mabello Indonesia adalah sebagai berikut; unity (kesatuan) yaitu merealisasikan bahwa tujuan berdagang adalah untuk meraih surga dan terhindar dari neraka-Nya, memberikan wadah dalam pemenuhan hak bagi unsur-unsur yang berperan langsung dalam pengembangan perusaha-an, salah satunya adalah mitra Mabello. Ini adalah wujud implementasi Mabello sebagai khalifah yang memberikan manfaat kepada individu tanpa mengorbankan individu lain. Equilibrium (keseimbangan) yaitu Mabello berlaku adil kepada setiap karyawan maupun pelanggannya. Setiap dari mereka diberikan kesempatan untuk menyampaikan kritik dan sarannya, sehingga saran-saran perbaikan bisa datang dari siapa saja. Free Will (Kehendak bebas) yaitu Mabello memberikan kebebasan kepada para karyawan untuk berkarya dan bersinergi demi majunya perusahaan. Dengan ini, Mabello mampu menghadirkan produk-produk yang inovatif dan up to date sehingga dapat memberikan kepuasan bagi para pelanggan-nya. Responsibility (tanggungjawab) yaitu usaha Mabello dengan melaku-kan pengawasan mutu produk yang akan dipasarkan dengan didimpingi oleh ahli farmasi untuk memastikan produk aman dikonsumsi oleh masyarakat. Selain itu Mabello telah mengantongi izin BPOM dan ke-terangan halal dari MUI. Benevolence (Kebajikan) yaitu Mabello meng-adakan kajian islami untuk para karyawan perusahaan, buka puasa bersama, selain itu melaksanakan kegiatan sosial seperti sedekah Jumat dan pembagian handsinitizer di masa pademi serta kegiatan tanggap bencana di Donggala, Palu, Riau dan lain-lain.

10 nilai- nilai macca dan 14 nilai-nilai malempu'terinternalisasi ke dalam 5 aksioma dasar etika bisnis Islam. 


\section{DAFTAR PUSTAKA}

Barus, E. E., \& Nuriani. (2016, September). Implementasi Etika Bisnis Islam (Studi pada Rumah Makan Wong Solo Medan). Jurnal Perspektif Ekonomi Darussalam, 2(2), 126.

Berman, \& Evans. (2003). Retail Management. Singapore: The McGraw-Hill Companies, Inc. Fauzan, \& Nuryana, I. (2014, Februari). Pengaruh Penerapan Etika Bisnis terhadap Kepuasan Pelanggan Warung Bebek Bakar H. Slamet di Kota malang. Modernisasi, 2(1), 29.

Iswanto, B. (2017, Agustus). Nilai Falah pada Kearifan Lokal dalam Perdagangan Perbatasan Indonesia-Malaysia. Jurnal Diskursus Islam, 5(2), 43.

Mahmud, A. H. (2000). SILASA Kumpulan Petuah Bugis-Makassar. Jakarta: Saudagar.

Mujahidin, A. (2016, Juli-Desember). Peranan Kearifan Lokal (Local Wisdom) dalam Pengembangan Ekonomi dan Perbankan Syaariah di Indonesia. Jurnal Ilmiah Syari'ah, 5(2), 154.

Murtiningsih. (2019). The Meaning of Macca na Malempu' (Smart and Honest), Warani na Magetteng (Brave and Assertive) in Bugis Luwu Society Toward Educational Philosophy Perspektif. Studia Humanitatis(3).

Nawatmi, S. (2010, April). Etika Bisnis dalam Perspektif Islam. Fokus Ekonomi (FE), 9(1), 21.

Oliver. (2006, Januari-Juni). Acognatif Model of The Antecedents and Consequence of Satisfaction Decision. Journal of Marketing Research, 17(2), 21.

Qamar, N. (2017). Menguak Nilai Kearifan Lokal Bugis-Makassar Perspektif Hukum dan Pemerintahan. Makassar: SIGn.

Rahim, A. R. (2011). Nilai-Nilai Utama Kebudayaan Bugis . Yogyakarta: Penerbit Ombak.

Sahri, \& Huzaini, M. (2017, Januari). Etika Bisnis Islam dan Dampaknya terhadap Kesejahteraan Pedagang Sapi. JEBI (Jurnal Ekonomi dan Bisnis Islam), 2(1), 18.

Syaifullah. (2014). Etika Jual Beli dalam Islam. Hunafa: Jurnal Studia Islamika, 11(2), 381.

Syarif, E. (2016, April). Integrasi Nilai Budaya Etnis Bugis Makassar dalam Proses Pembelajaran sebagai Salah Satu Strategi Menghadapi Era Masyarakat ekonomi ASEAN (MEA). Jurnal Teori dan Praktisi Pembelajaran IPS, 1(1), 15.

Tjiptono. (2006). Pemasaran Jasa. Malang: Bayumedia Publishing.

Yusuf, M. (2013). Relevansi Nilai-Nilai Budaya Bugis dan Pemikiran Ulama Bugis. El Harakah, 15(2), 200.

Zethaml, \& Bitner. (2001). Service Marketing . UpperSaddle: Prentice Hall. 